\title{
Does occupational exposure to brown coal dust cause a decline in lung function?
}

\author{
Catherine Finocchiaro, Andrew Lark, Michael Keating, Antony Ugoni, Michael Abramson
}

Department of

Epidemiology and

Preventive Medicine,

Monash University

C Finocchiaro

A Lark

M Abramson

Regional Respiratory

Service, Latrobe

Regional Hospital,

Traralgon

M Keating

Department of Public

Health and

Community Medicine,

University of

Melbourne

A Ugoni

Correspondence to:

Dr M Abramson,

Department of Epidemiology

and Preventive Medicine,

Monash Medical School,

Alfred Hospital, Prahran,

Victoria 3181, Australia.

Accepted 26 February 1997

\begin{abstract}
Objectives-To determine if the rate of change in forced expiratory volume in one second $\left(F E V_{1}\right)$ in subjects with high exposure to Latrobe Valley brown coal dust was significantly greater than the rate of change among subjects with low exposure.

Methods-A retrospective dynamic cohort design with variable time windows. This study was conducted over a period of 14 years from 1980 to 1994 and used data collected by the State Electricity Commission (SEC) Lung Function Unit for an asbestos surveillance programme. The subjects were exposed to low, medium, or high levels of coal dust. Basic spirometry with wedge bellows spirometers was used to assess lung function. A general linear model (GLM) was used to assess the effects of smoking and exposure to coal dust upon the change in forced expiratory volume in one second $\left(F_{E V}\right)$ while adjusting for age and height.
\end{abstract}

Results-The mean (95\% confidence interval $(95 \% \mathrm{CI})$ ) rate of decline in $\mathrm{FEV}$, was 40 (36 to 44$) \mathrm{ml} / \mathrm{year}$. Age was a significant predictor of change. A significant effect was found for smoking $(P=0.02)$ and for exposure to coal dust $(P=0.008)$. The only significant difference with exposure to coal dust was between the high and mixed exposure categories.

Conclusion-There is no convincing evidence of excessive decline in $F E V$ with exposure to coal dust $>0.75 \mathrm{mg} / \mathrm{m}^{3}$. The absence of a dose response relation provides some evidence against a causal relation. On the basis of this study, reduction of the exposure standards currently applied to brown coal dust in the Victorian electricity industry is not warranted to prevent respiratory disease.

(Occup Environ Med 1997;54:642-645)

Keywords: coal dust

Little is known about the relation between occupational exposure to brown coal dust and decline in respiratory function. This is in contrast to the well documented relations between exposure to black coal dust, coal workers' pneumoconiosis, and chronic airflow limitation. ${ }^{1}$

Soft brown coals contain $30 \%-65 \%$ moisture, up to $15 \%$ mineral ballast, and provide $1800-3000 \mathrm{kcal} / \mathrm{kg}$ of energy. The organic components of brown coal are bitumen and humic material - the organic decomposition products of plants and animals. Lignite, together with kylite, is classified as a soft brown coal. $^{2}$

The Latrobe Valley of eastern Victoria contains extensive and easily accessible deposits of lignite. Total brown coal resources have been assessed at more than 98000 million tonnes-about one quarter of Australia's readily available fossil fuels. This coal has been mined by the open cut method since 1924 for the generation of electricity by nearby power stations under the auspices of the State Electricity Commission (SEC). Over $80 \%$ of Victoria's electricity is supplied in this way.

Brown coal dust is ubiquitously present in the working environments of the mines and power stations and with the exception of workers in offices and laboratories, all personnel are exposed to it. The brown coal is pulverised and undergoes a combustion process in huge boilers. As part of this process, gas and dust are drawn off to precipitators that separate the gas from the dust electrostatically. The gas is then vented to the atmosphere through the chimney or stack. The precipitators have to be cleaned periodically. Human exposure to precipitator dust occurs if respiratory protective equipment is not used effectively.

Health hazards associated with exposure to brown coal dust were reviewed by Baird in $1983 .^{3}$ Although animal studies suggested that lignite dust may elicit lung reactions similar to reactions from harder coals, the findings were inconclusive. An extensive cross sectional study of the respiratory health of SEC employees in relation to exposure to coal dust was carried out by an occupational hygienist Richard Rawling between 1980 and 1986. That study identified some discrepancies between objective and subjective findings and showed a lack of any significant difference in lung function variables between more heavily and lightly exposed groups which would indicate airways obstruction. ${ }^{4}$ However, a notable increase in symptoms of cough, low grade breathlessness, wheeze, and phlegm did occur in the more heavily exposed group.

The objective of the present study was to determine if the rate of change in forced expiratory volume in one second $\left(\mathrm{FEV}_{1}\right)$ in subjects with high exposure to Latrobe Valley brown coal dust was significantly greater than the rate of change among subjects with low exposure. 


\section{Methods}

The study design chosen was a retrospective dynamic cohort design with variable time windows. This study was conducted over a period of 14 years from 1980 to 1994 and used data collected by the SEC Lung Function Unit for an asbestos surveillance programme. Recruitment took place between 1980 and 1988. A few subjects retired during the course of the study period. In these cases, it was assumed that exposure to coal dust and welding fumes ended at the time of retirement.

SUBJECTS

Subjects were recruited from the workforce of the State Electricity Commission of Victoria. Criteria for inclusion included mainly subjects who worked in the Latrobe Valley and some who worked at the Newport power station in Melbourne, who had lung function tests on two or more occasions over a period of at least six years in whom it was possible to measure change in FEV, accurately. Out of about 4000 employees who had at least one lung function test, 448 subjects met the inclusion criteria. Newport power station used natural gas as its fuel, so employees were not exposed to the dust of brown coal or its derivatives.

Subjects excluded from the study were those with asthma and subjects on bronchodilator treatment $(n=38)$, on the grounds that $\mathrm{FEV}_{1}$ was not reproducible in asthmatic patients. However, a history of childhood asthma alone was not considered grounds for exclusion. Subjects with asbestosis $(n=5)$ or the combination of asbestosis and asthma $(n=1)$ were also excluded. However, those with a few pleural plaques were not excluded as pleural plaques do not affect lung function unless extensive. Others excluded from the study were subjects with systemic lupus erythematosus $(n=1)$, those who were technically difficult to test $(n=2)$, and those who had insufficient occupational or lung function data $(n=13)$, making a total of 60 subjects who were excluded from the study.

\section{ASSESSMENT OF EXPOSURE}

With the exception of office or laboratory based personnel, subjects who worked in a power station or a mine for the duration of the study period were classified as having high exposure to coal dust. Those classified as having low exposure included office and laboratory workers, subjects working at the gas fired Newport power station, and those who worked outside in non-mining areas-for example, gardeners. Subjects were classified as having mixed exposure if they worked for half of the study period in a high exposure job and half in a low exposure job; or if their exposure to coal dust could not be confidently classified. Subjects who retired during the study period were assumed to have negligible exposure to coal dust from the time of retirement (table 1).

Based on the data obtained from Rawling's study, ${ }^{4}$ the cut off between high and low exposure was taken as an estimated mean personal exposure to total dust of $0.75 \mathrm{mg} / \mathrm{m}^{3}$. Subjects
Table 1 Tasks occupying groups exposed to low, medium, and high concentrations of brown coal dust ${ }^{4}$

Low:

Tradesmen and associated occupations:

Mechanical, transport, and electrical

Fitting and turning, boiler making

Motor mechanic and electrical fitting

Engineers and scientific assistants

Subjects at Newport power station:

Carpenters, builders, gardeners, and supervisors of civil works

Overseers in areas other than above

Unit controllers in power station control rooms

Storemen

Other subjects with low exposure occupational histories.

Mixed:

Plumbers, fitters, electricians, boilermakers

Foremen, supervisors, and overseers to tradesmen

Turbine drivers, unit attendants, and controllers

Riggers, crane drivers

Trimmer, fireman, boilerhouse engineer

Labourers and builders' labourers

Work coordinators and planners

Battery fitters

High:

Operators, firemen, or attendants in power stations

Cleaners or boiler cleaners in power stations

Tradesmen or trade assistants in power stations

Riggers in power stations

Bricklayers and builders in power stations

Unit attendants at Hazelwood power station

Workers in mines

were thus classified as having high, low, or mixed exposure to coal dust.

LUNG FUNCTION TESTING

Basic spirometry with wedge bellows spirometers (Vitalograph, Buckingham, UK) was performed on the subjects who participated in the Rawling study over the period 1983-4. Subse-quently, after cross calibration a pneumotachograph (Hewlett Packard, Waltham, USA ) was used to measure $\mathrm{FEV}_{1}$. This was carried out by SEC occupational nurses in the Latrobe Valley, who were trained in spirometry. Quality assurance of the testing programme was done by the respiratory scientist. $\mathrm{FEV}_{1}$ was measured in accordance with American Thoracic Society guidelines. ${ }^{5}$ Before each testing session, each spirometer was calibrated with a three litre syringe. Also, exponential waveforms from an explosive decompression device were used weekly to assess the dynamic accuracy of the pneumotachograph.

STATISTICAL ANALYSIS

Data obtained from files was stored in a database specifically designed for this study The mean age of the subjects between the first and last tests was calculated, as was the rate of change in FEV, between the first and last tests, assuming that the rate was linear. Data from intervening tests were not used. The data were then read and analysed within SAS. ${ }^{\circ}$ A general linear model (GLM) was used to assess the effects of smoking and exposure to coal dust upon the change in $\mathrm{FEV}_{1}$ while adjusting for age and height. The GLM was fitted twice, with the inclusion of an interaction between smoking and coal dust in the first model, and only the main effects of smoking and coal dust in the second (as the interaction was not significant). Bonferroni $95 \%$ confidence intervals (95\% CIs) were then used to assess comparisons between pairs of means. ${ }^{7}$ 
A power calculation was performed for a two sample $t$ test with unequal group sizes and assuming that a two tailed significance at the 0.05 level was required. The power of the study to detect a clinically important difference of 20 $\mathrm{ml} /$ year in rate of change in $\mathrm{FEV}_{1}$ between the groups with low and high exposure was greater than $95 \%$. The power of the study to detect a $10 \mathrm{ml} /$ year difference in rate of change in $\mathrm{FEV}_{1}$ was $56 \%$; but only $18 \%$ to detect the $5 \mathrm{ml} /$ year difference that would be expected from the literature. ${ }^{8}$ The SDs of the groups with high and low exposures to coal dust were used in the power calculations.

\section{ETHICAL ISSUES}

The major ethical issues relating to this research project were maintaining the confidentiality of personal medical records and the fact that informed consent was not sought from individual participants. It would have been impractical to seek individual consent from the many subjects. Because of the downsizing of the industry and natural retirement, many subjects were no longer employed in the industry. In lieu of obtaining individual consent and in line with guidelines on ethics in occupational epidemiology, support for the project was obtained from management and unions. The study was then approved by the standing committee on ethics in research on humans at Monash University.

\section{Results}

All subjects were men and each subject's height as recorded at the first and last tests was usually the same. The average duration of follow up was eight years.

There was a wide variety in occupations, with the occupation of over half the subjects changing in some way during the course of the study. This further complicated the determina-

Table 2 Descriptive statistics for decline in FEV, within smoking groups (measurements in $\mathrm{ml} / \mathrm{y})$

\begin{tabular}{llllllll}
\hline & $n$ & Mean & (SD) & SEM & Min & Max & (95\% CI) \\
\hline Non-smokers & 112 & 33.7 & $(44.6)$ & 4.2 & -120 & 140 & $(25.3$ to 42.0$)$ \\
Ex-smokers & 114 & 36.6 & $(40.1)$ & 3.8 & -80 & 140 & $(29.1$ to 44.0) \\
Smokers & 162 & 46.5 & $(35.4)$ & 2.8 & -40 & 140 & $(41.1$ to 52.0$)$ \\
\hline
\end{tabular}

Table 3 Descriptive statistics for decline in FEV, within exposure groups (measurements in $\mathrm{ml} / \mathrm{y}$ )

\begin{tabular}{llllllll}
\hline Exposure to coal dust & $n$ & Mean & (SD) & SEM & Min & Max & (95\% CI) \\
\hline Low & 172 & 39.9 & $(40.0)$ & 3.0 & -90 & 140 & $(33.9$ to 45.9$)$ \\
Mixed & 98 & 30.7 & $(40.8)$ & 4.1 & -120 & 130 & $(22.5$ to 38.9) \\
High & 118 & 47.5 & $(37.8)$ & 3.5 & -70 & 140 & $(40.7$ to 54.4) \\
\hline
\end{tabular}

Table 4 General linear model of decline in FEV, by smoking and exposure to coal dust; with age and height as covariates

\begin{tabular}{lllllc}
\hline Source of variation & $\begin{array}{l}\text { Sum of } \\
\text { squares }\end{array}$ & $\begin{array}{l}\text { Degrees of } \\
\text { freedom }\end{array}$ & Mean square & F value & $P$ value \\
\hline Covariates: & & & & & \\
$\quad$ Age & 0.0523 & 1 & 0.0523 & 37.2 & $<0.0001$ \\
$\quad$ Height & 0.0000137 & 1 & 0.0000137 & 0.01 & 0.92 \\
Main effects: & & & & & \\
$\quad$ Smoking & 0.0111 & 2 & 0.00554 & 3.94 & 0.02 \\
$\quad$ Coal dust & 0.0137 & 2 & 0.00687 & 4.89 & 0.008 \\
Model & 0.0810 & 6 & 0.0135 & 9.6 & $<0.0001$ \\
Error & 0.536 & 381 & 0.00141 & & \\
Corrected total & 0.617 & 387 & & & \\
\hline
\end{tabular}

tion of exposure categories for exposure to coal dust. Occupational histories that indicated exposure to welding fumes were fewer than anticipated. Of the 388 subjects included, only 16 had any exposure to welding fumes.

Smoking status was classified as at the time of the first test, however, it was noted that the smoking status did not always remain constant. Although the changes have not been measured, the general impression was that more smokers stopped than resumed.

DECLINE IN FEV

The mean $(95 \% \mathrm{CI})$ rate of decline in $\mathrm{FEV}_{1}$ was 40 (36 to 44 ) $\mathrm{ml} /$ year. Tables 2 and 3 show the descriptive statistics for the mean decline in $\mathrm{FEV}_{1}$ within the smoking and coal dust exposure subgroups respectively.

The first GLM found that the covariate age was a significant predictor of change in $\mathrm{FEV}_{1}$ $(P<0.0001)$, but that height was not $(P=0.87)$. The interaction beween smoking and coal dust was not significant $(P=0.33)$. The mean rate of decline in $\mathrm{FEV}_{1}$ after adjustment for age and height did not differ much between the various smoking and coal dust combinations (results not shown).

The second GLM, which excluded the interaction between smoking and coal dust, found that age was still a significant predictor of change in $\mathrm{FEV}_{1}(\mathrm{P}<0.0001)$, but height was not $(\mathrm{P}=0.92$, table 4). Height was left in the model, however, as it was known to be an important predictor of initial lung function. A significant effect was found for smoking $(\mathrm{P}=0.02)$ and for exposure to coal dust $(\mathrm{P}=0.008)$. Table 5 shows the Bonferroni $95 \%$ CIs. There was a significant difference in mean rate of decline in FEV, between current smokers and non-smokers. However, the only significant difference with exposure to coal dust was between the high and mixed exposure categories.

\section{Discussion}

The effects of age and cigarette smoking on decline in $\mathrm{FEV}_{1}$ evident from this study are consistent with the literature. Smoking is a well known risk factor for excessive decline in $\mathrm{FEV}_{1}{ }^{9}{ }^{9}$ The effect of smoking may have been underestimated by only classifying subjects' smoking status on entry to the study. However, we have previously found in the aluminium industry that reported cigarette smoking was highly reproducible $(\kappa=0.92)$ and was unchanged in $92 \%$ of workers over 12 months. ${ }^{10}$

Although we found a significant difference in the mean rates of decline in FEV between the coal dust exposure categories, the lowest mean decline was shown in the mixed exposure category, rather than the low exposure category as would have been expected if there was a monotonic relation.

Thus we think that there is no convincing evidence of excessive decline in $\mathrm{FEV}_{\text {, with }}$ exposure to coal dust $>0.75 \mathrm{mg} / \mathrm{m}^{3}$. The absence of a dose-response relation provides some evidence against a causal relation. There was sufficient statistical power to find a clinically important difference between high and low exposure groups, had one existed. 
Table 5 Differences in means and 95\% CIs (by Bonferroni's method) for rates of decline in FEV $(\mathrm{ml} / \mathrm{y})$ between smoking and exposure to coal dust

\begin{tabular}{|c|c|c|}
\hline Comparison & $\begin{array}{l}\text { Difference } \\
\text { in means }\end{array}$ & $(95 \% C I)$ \\
\hline Smokers $v$ ex-smokers & 10.0 & $(-1.1$ to 21.0$)$ \\
\hline Smokers $v$ non-smokers & 12.9 & ( 1.8 to 24.0 ) \\
\hline Ex-smokers $v$ non-smokers & 2.9 & $(-9.1$ to 14.9$)$ \\
\hline High $v$ mixed coal dust & 16.8 & ( 4.5 to 29.2 ) \\
\hline High $v$ low coal dust & 7.7 & $(-3.1$ to 18.4$)$ \\
\hline Mixed $v$ low coal dust & -9.2 & $(-20.6$ to 2.2$)$ \\
\hline
\end{tabular}

How do these findings compare with other cohort studies in dusty occupations? The annual declines in $\mathrm{FEV}_{1}$ from five separate studies have been averaged. ${ }^{8}$ It is interesting to note that the average decline for non-smokers and non-exposed workers is much the same (43 $\mathrm{ml} / \mathrm{y}$ ). The effect of dust exposure (mean decline $48 \mathrm{ml} / \mathrm{y}$ ) seems to be less than that of smoking $(51 \mathrm{ml} / \mathrm{y})$. One study which reported a very low rate of $9 \mathrm{ml} /$ year in non-exposed subjects was excluded as an outlier. Otherwise the mean rates are comparable in magnitude to those obtained in the current study. The most complete study of exposure to coal dust carried out in the brown coal industry was a cross sectional study that did not include an estimate of cumulative exposure. ${ }^{4}$ Cross sectional studies can provide information about association, but do not usually provide strong evidence for causation.

The low exposure group in the current study is equivalent to the non-exposed group in Rawling's study ${ }^{11}$ that included machinists, cleaners, turbine drivers, storemen, and transport drivers. The corresponding mean total dust exposure was well under $0.75 \mathrm{mg} / \mathrm{m}^{3}$. These data were used in the current study to provide an estimate of exposure to coal dust during the period of follow up, but give no information on cumulative exposure over an entire working lifetime. The formal examination of cumulative exposure to coal dust was beyond the scope of the current study.

More difficulty was also encountered in classifying exposure to coal dust in the current study than expected. The boundaries between the high and mixed groups and between the low and mixed groups were not distinct. Further analysis (not presented) confirmed that no significant difference in the mean decline in $\mathrm{FEV}_{1}$ existed between exposure groups. This analysis found that no threshold level of effect existed between the group with low exposure to coal dust and the groups with mixed and high exposures combined, or between the groups with low and mixed exposures combined and the high exposure group. It is thus unlikely that misclassification of coal dust exposure has seriously affected the results presented.

This study had potential sources of bias, of which the main one is selection bias. Subjects were selected because of their repeated participation in the asbestos surveillance programme over a period of at least six years (388 out of 4000 , about $10 \%$ ). However, there is little reason to suspect that concerns about exposure to coal dust in itself would have greatly affected participation in the asbestos surveillance programme. It is therefore thought that the results could be generalised to the whole workforce.
Exposure to welding fumes (which contain the irritant gases nitrogen dioxide and ozone) were a potential confounding factor. However, when included as an independent variable in the analysis, exposure to welding fumes was not significantly related to decline in lung function. The fact that only 16 employees had any exposure was surprisingly low considering the nature of work in this industry and it is possible that the effects of exposure to welding fumes have been underestimated in this study. There is also potential confounding by exposure to asbestos. Asbestos dust has been reported to have obstructive as well as restrictive effects. ${ }^{12}$ However, given that only six cases of diagnosed asbestosis occurred in over 4000 subjects, the degree of confounding would be minimal.

\section{Conclusions}

On the basis of this study, reduction of the exposure standards currently applied to brown coal dust in the Victorian electricity industry is not warranted to prevent respiratory disease. Exposure to brown coal dust and its derivatives should, however, continue to be monitored to ensure that exposure is kept as low as possible and that current exposure limits are not exceeded.

Because this study confirmed a significant association between smoking and decline in lung function in this industry, employees and others involved in the industry should continue to be encouraged to become or remain non-smokers through workplace health promotion strategies.

We thank the Management and Unions of Generation Victoria and Energy Brix Australia for making this research possible. The and Energy Brix Australia for making this research possible. The study was funded by Generation Victoria. Thanks are due to John Drewitt from the SEC and Leo Ruschena from Yallourn
Power for access to workers and records, Simon McKenzie and Power for access to workers and records, Simon McKenzie and
Glen Tunny of ElTc for the database program, Mary Swanton Generation Victoria Librarian, for assistance with the literature search, Graeme Sennett, and Norma Hicks of Corporate Human Resources, Generation Victoria, for assistance in the data entry phase. We thank Richard Rawling for giving us permission to reproduce occupational hygiene data.

1 Souter CA. Update on lung disease in coal miners. $B r \mathcal{F}$ Ind Med 1987;44:145-8.

2 Stahl R. Coal and derivatives. In: Parmeggiani L, ed. Encyclopaedia of occupational health and safety, 3rd ed. Geneva: International Labour Organisation, 1983:487-90.

3 Baird AH. Health hazards associated with the industrial utilisation of lignite coal: literature review and consideration of epidetion of lignite coal: literature review and consideration of epide-
miological strategies within the State Electricity Commission of miological strategies within the State Electricity Commission of
Victoria, Australia. Dissertation, University of London, Victoria,

4 Rawling R. Respiratory health of electricity industry workers exposed to lignite coal dust [MPH thesis]. Sydney: University of Sydney, 1989:195.

5 Gardner RM, Hankinson JL, Clausen JL, et al. Standardisation of spirometry - 1987 update. Am Rev Respir Dis 1987; 136:1285-98.

6 SAS Institute. SAS/STAT user's guide, version 6, 4th ed. Vol 2. Cary, NC: SAS Institute 1990:891-996.

7 Dawson-Saunders B, Trapp R. Basic and clinical biostatistics. California: Appleton and Lange, 1990.

8 Becklake MR. Occupational exposures: evidence for a causal association with chronic obstructive pulmonary discase. Am Rev Respir Dis 1989;140:885-91.

9 Fletcher CR, Peto R, Tinker C, Speizer F. The natural history Fletcher CR, Peto R, Tinker C, Speizer F. The natural history of chronic bronchitis
sity Press, 1976.

sity Press, 1976 .
10 Abramson M. Bronchial reactivity in aluminium smelter workAbramson $\mathrm{M}$. Bronchial reactivity in aluminium smelter work-
ers [PhD thesis]. Newcastle: University of Newcastle, 1989:217.

11 Rawling R. Epidemiology of Victorian power workers exposed to lignite coal dust. Presented to the Annual Conference of the Australian Institute of Occupational Hygienists, Melbourne, 1982. Melbourne: AIOH, 1982.

12 Seaton A. Asbestos related diseases. In: Morgan WKC, Seaton A, eds. Occupational lung diseases, 2nd ed. Peaton A, eds. Occupational lung dis 